\title{
O PROJETO DE UMA MEMÓRIA FREUDIANA: UMA ANÁLISE ACERCA DA CONSTITUIÇÃO DESSA NOÇÃO NOS PRIMÓRDIOS DA PSICANÁLISE
}

\author{
Maria Celina Lima Peixoto \\ Débora Passos de Oliveira ${ }^{2}$
}

RESUMO: O presente trabalho versa sobre a constituição da noção de memória na teoria freudiana. Para tanto, utilizamos, de modo primordial, as elaboraçóes desenvolvidas no Projeto para uma psicologia científica. Objetivamos ressaltar que Freud subverte a problemática acerca do conceito de memória, concedendo a essa ideia um caráter criativo que se diferencia da simples representação de um objeto contido na realidade material. Em Freud, a memória excede o que se compreende comumente como evocação, ou seja, a lembrança não se restringe à retomada de uma percepção. Se a memória é considerada como sendo o próprio psiquismo, é a sua relação com a pulsão e, posteriormente, com a noção de a posteriori (Nachträglich) que possibilita a efetivação de uma memória própria à Psicanálise. Desse modo, explicitamos que a memória em Freud é tanto um imperativo da pulsão quanto o desdobramento dos efeitos de uma temporalidade psíquica. Mesmo que parta de uma construçáo teórica estritamente associada às ciências naturais, um exame mais detido a respeito das formulaçóes desse período nos ajuda a compreender a maneira como ele arquiteta uma teoria que, pelo menos a princípio, tinha como objetivo último esclarecer a problemática concernente à noção de memória.

PALAVRAS-CHAVE: Memória. Percepção. Pulsão. Nachträglich.

Doutora em Psicologia pela Université Paris 13, Professora do PPG-PSI da Universidade de Fortaleza, Coordenadora do LEIPCS (Laboratório de Estudos e Intervençôes Psicanalíticas na Clínica e no Social).E-mail: celina.lima@unifor.br

2 Mestre pela Universidade de Fortaleza (UNIFOR), bolsista pela FUNCAP (Fundação Cearense de Apoio ao Desenvolvimento Científico e Tecnológico). E-mail: deboraoliveira@edu.unifor.br 


\section{INTRODUÇÁo}

Parafraseando Guimarães Rosa ${ }^{3}$, poderíamos dizer que, em cada análise que se inicia, a Psicanálise torna a começar. Mais que uma construçáo poética, essa frase aponta para o que existe de mais essencial numa análise: seu caráter de singularidade. Em cada divã, uma história individual. Em cada história, uma narrativa. E em cada narrativa, uma memória. Acontecimentos de uma vida - com suas alegrias, tristezas, prazeres e dissabores - tecem as lembranças de cada um. Dizer isso é, desde logo, anunciar que a Psicanálise é uma práxis que se detém sobre a memória. Entretanto, de que memória nos fala Freud? Contrariamente ao senso comum, que pensa a memória como um armazenamento de experiências disponíveis à evocação, Freud a concebe a partir de um caráter inventivo, o qual, conforme Casanave (2008), se refere à capacidade da memória de instaurar novos sentidos com base no material proveniente da experiência.

De acordo com Laplanche e Pontalis (1992), Freud não sistematiza, ao longo de sua obra, uma teoria sobre a memória. Entretanto, não podemos deixar de dar relevo àquilo que ele afirma, com ênfase, no Projeto. Com suas palavras: "Qualquer teoria psicológica digna de consideração precisa fornecer uma explicação para a memória" (1895/2007, p. 343). Ao relacionarmos essas duas passagens, onde a primeira se refere a um exame ulterior relativo ao construto teórico freudiano e a segunda alude a um possível desejo de Freud com relação aos encaminhamentos de sua obra, uma inquietude se anuncia. Será que a aspiração expressa por ele, em 1895, não ultrapassa os limites de um manuscrito que foi, pelo próprio autor, deixado de lado?

A relação que Freud manteve com a produção desse artigo é de conflito e expectativa. Em carta a Fliess, no período da construção do texto, anuncia: "A psicologia é realmente um calvário para mim, jogar boliche ou colher cogumelos no campo são, certamente, atividades muito mais saudáveis" (1895/2007, p. 326). Já em um momento posterior, confidencia: “[...] de repente as barreiras caíram por terra [...] Tudo pareceu encaixar-se e as engrenagens se ajustavam, dando a impressão de que o conjunto era realmente uma máquina que logo começaria a andar sozinha” (FREUD, 1985/2007, p. 326). A despeito, ou em consequência, das sensações desprazerosas e das esperanças grandiosas, Freud renuncia ao Projeto ou, pelo menos, à proposta de explicar os processos psíquicos mecanicamente. No entanto, podemos

3 "Minha Senhora Dona: um menino nasceu - o mundo tornou a começar!" (ROSA, 2001, p. 484). 
nos aventurar a dizer que o seu plano de formular uma compreensão sobre a organização dos traços mnêmicos permanece no decorrer de sua obra, sendo este o projeto que não foi descartado.

Iniciar uma análise sobre a memória freudiana a partir de um exame acerca do Projeto não constitui uma escolha arbitrária. Se, em alguns textos, precedentes ao manuscrito de 1895, Freud já empreende uma análise a respeito da constituição dos traços mnêmicos, sobretudo com base em uma investigação a respeito do conceito de representação (Vorstellung), é apenas no Projeto que identifica o inconsciente com o próprio psíquico. Dessa maneira, na monografia freudiana sobre as afasias, texto anterior ao Projeto, a memória ainda não é concebida como algo psíquico. Nas palavras do autor: "É muito duvidoso que essa modificação esteja de algum modo associada com algo psíquico. Nossa consciência não contém nada que possa justificar, do ponto de vista psicológico, o termo imagem latente de recordaçáo [...]” (FREUD, 1915a/2007, p. 206)4 .

Conforme Simanke e Caropreso (2005), a possibilidade de um psiquismo inconsciente é aceita apenas no Projeto. Assim, Freud revela, em 1895, o que seria, a partir de então, o cerne de sua teoria: "Temos tratado os processos psíquicos como algo que poderia carecer deste conhecimento através da consciência, que existe independente de uma consciência" (1895/2007, p. 352). A proposta de um psiquismo inconsciente não se restringe às formulaçóes do Projeto; pelo contrário, atravessa toda a teoria freudiana, sendo o seu pressuposto principal. Nesse sentido, podemos observar, em um artigo já tardio, explanaçóes admiravelmente semelhantes às desenvolvidas em 1895. Nas palavras de Freud ([1940]/1938/2007, p. 156): "Enquanto a psicologia da consciência nunca saiu daquelas séries lacunares, que evidentemente dependem de outra coisa, a concepçáo segundo a qual o psíquico é em si inconsciente permite configurar a psicologia como uma ciência natural entre outras".

A noção de psíquico inconsciente é também nosso pressuposto básico para os estudos sobre a memória freudiana. Desde o momento em que Freud desvincula as ideias de psiquismo e de consciência, a independência dos processos representacionais, corolário da memória, advém. Em contrapartida, dizer que o inconsciente é constituído pelos traços mnêmicos é ainda dizer muito pouco sobre a memória, em Freud. É preciso um exame aprofundado, por essa equivalência, para que as características imprescindíveis do psiquismo

\footnotetext{
${ }^{4}$ A monografia freudiana, intitulada Zur Auffassung der Aphasien, não foi adicionada por Strachey às obras completas de Freud. Apenas uma parte de suas formulaçôes é apresentada no apêndice do artigo sobre o inconsciente, de 1915.
} 
como um aparelho de memória, possam emergir. Uma investigação sobre a memória problematiza, desse modo, toda a compreensão da relação entre a consciência e o inconsciente.

Que o estudo da memória em Freud esteja balizado na noção de psíquico inconsciente significa, pois, uma ideia de representação especificamente freudiana. Com efeito, se a memória freudiana é constituída por representaçóes, e se essa mesma memória é, prioritariamente, inconsciente, podemos falar, a partir da Psicanálise, de um tipo de representação alheia a uma determinada tradição filosófica.

É interessante notarmos que as formulaçôes freudianas sobre a noção de memória foram, desde o início, balizadas pelo seu interesse de Freud em fazer da Psicanálise uma ciência equiparável às ciências naturais. Esse fato marca o horizonte das pesquisas freudianas, uma vez que o objeto de estudo da Psicanálise necessita apresentar-se no âmbito da realidade material. Não à toa, as primeiras elaborações sobre a memória apresentam-se já no Projeto, no qual Freud oferece uma tentativa de elucidar os processos psíquicos à luz de explicaçóes próprias às ciências naturais.

\section{O PROJETO DE UMA MEMÓRIA EM FreUd: UMA REPRESENTAÇÁo INCONSCIENTE}

O Projeto enfoca uma nova configuração da noção de memória, que náo se confunde com a ideia de cópia de um objeto e que, segundo Laplanche e Pontalis (1992), comporta a melhor via para o entendimento da organizaçáo dos traços mnêmicos. De acordo com os autores, Freud pretende explicar, nessa obra, a efetivação do traço mnêmico sem utilizar, para esse fim, uma relação de semelhança entre a inscrição da percepção no psiquismo e a imagem do objeto na realidade. Nesse texto, Freud, ainda preso a uma linguagem própria às ciências naturais, diferencia os neurônios da percepção $(\varphi)$ daqueles da memória $(\psi)$. Não atribui, no entanto, uma essência distintiva a ambos, como fazia a literatura médica corrente na época, mas uma diferença fundamentada nas quantidades (Q) com que precisam lidar. Por conseguinte, os neurônios não são qualitativamente diferentes entre si, contudo, divergem quanto à finalidade a que estão reservados.

Freud identifica os neurônios da memória $\psi$, onde se formam as representaçóes, com o próprio psiquismo. Conforme sua compreensão, existem os neurônios permeáveis, que estáo a serviço da percepção, e os 
neurônios impermeáveis, que comportam a memória e, provavelmente, os processos psíquicos em geral.

Desse modo, os neurônios perceptivos seriam aqueles que permitem a livre passagem da quantidade de origem exógena, conservando, por essa razão, seu estado inalterado. Em contrapartida, os neurônios da memória se caracterizam por, se não impedir, ao menos dificultar o fluxo excitatório, e é precisamente isso que possibilita a alteração destes. Além disso, Freud divide o sistema mnêmico em dois: $\psi$ do manto, relacionado ao sistema perceptivo, e $\psi$ do núcleo, conectado ao interior do corpo. Os neurônios encarregados da memória estão fora de contato com o mundo externo; dessa forma, recebem excitação apenas a partir dos neurônios da percepção e da parte interna do organismo. Freud estabelece a capacidade dos neurônios da memória de reter a passagem da excitação através de barreiras de contato entre os neurônios $\psi$, que não são mais que grades que impedem o livre escoamento da quantidade. São as barreiras de contato, pois, que possibilitam a efetivação da memória.

A proposta de Freud consiste em formular uma teoria psicológica como ciência natural. Para isso, ele associa a teoria da inércia, que diz respeito à descarga total de Q (quantidade), ao funcionamento neuronal. Em suas palavras, "[...] apresentar os processos psíquicos como estados quantitativamente determinados de partículas materiais comprováveis (os neurônios)" (FREUD, 1895/2007, p. 339). É, porquanto, por essa junção entre atividade neuronal e rebaixamento de $\mathrm{Q}$ que Freud procura explicitar o que caracteriza o psiquismo - a saber, sua capacidade de ser alterado de maneira duradoura, da mesma forma que permanece passível a novos registros. Essa alteração no psiquismo refere-se aos traços mnêmicos oriundos da percepção, e a função que se relaciona a esses traços é, assim, denominada memória. Segundo ele, “[...] em nosso aparelho psíquico permanece um traço das percepçóes que incidem sobre ele. A estes podemos descrever como traços mnêmicos, e à função que com ele se relaciona damos o nome de memória" (FREUD, 1900/2007, p. 531).

Entretanto, a finalidade de apresentar a inscrição dos traços mnêmicos com base na teoria da inércia é problemática sob vários aspectos. $\mathrm{O}$ principal deles é que qualquer explicação sobre o psiquismo que comporte a memória se depara com a dificuldade de admitir que, após uma passagem de excitação, permaneça um traço duradouro. Freud começa a delinear uma das principais particularidades de sua memória, a saber, a capacidade de conservação permanente do traço mnêmico. 


\section{A MEMÓRIA COMO IMPERATIVO DA VIDA}

Se no início do Projeto, Freud estabelece como objetivo interpretar o psiquismo de acordo com a teoria da inércia, logo o autor precisa fazer uso de um novo princípio, o da constância. Por que Freud se vê obrigado a introduzir esse novo primado? Atribui ao princípio de inércia o modelo reflexo, no qual a fuga do estímulo é o padrão. Em contrapartida, nosso organismo é excitado também a partir do seu interior. Enfatiza Freud: "Esses estímulos se originam nas células do corpo e criam as grandes necessidades: fome, respiração, sexualidade" (1895/2007, p. 341). O organismo náo pode, dessa maneira, utilizar a quantidade de excitação para fugir do estímulo desprazeroso. $\mathrm{O}$ cancelamento de uma fonte interna de excitação dependeria de uma ação mais complexa sobre o mundo, tal como a obtenção do alimento. Seria necessário aquilo que Freud chama de açấo especifica, para que ocorresse a cessaçáo do estímulo.

A falta de proteção do psiquismo contra os estímulos endógenos determina a modificação do princípio de inércia para o princípio de constância. No entanto, o princípio de constância não se opôe ao princípio de inércia; pelo contrário, trabalha em seu favor, permitindo que a quantidade interna de excitação seja, de fato, descarregada de modo adequado. Não seria esta uma primeira apresentação daquilo que Freud anuncia, em 1920, sobre a relação entre pulsão de morte e pulsão de vida? O autor salienta: "A meta de toda a vida é a morte [...]" (FREUD, 1920/2007, p. 38).

Segundo Freud (1895/2007), o psiquismo se vê coagido a renunciar à originária propensão ao estado de inércia, isto é, ao nível zero. Precisa admitir, desse modo, um acréscimo de excitação. É para dar conta dos estímulos endógenos que se estabelecem os trilhamentos da memória com a fixaçáo (Fixierung) do traço. Seguindo o raciocínio da função primária relacionada à inércia e da secundária, associada à constância, Gabbi afirma que, “[...] se a primeira está ligada ao externo, ao que não é ainda vivo - um retorno ao estado inicial de inércia - na segunda, assinala-se a necessidade de se introduzir a memória como conseqüência dos imperativos internos, da própria vida” (GABBI, 1987, p. 98).

Assim, podemos observar que o surgimento do interno ou, mais precisamente, dos traços de memória, relaciona-se às necessidades corporais, isto é, à exigência de trabalho psíquico que estas impóem. Nesse sentido, Freud atribui, no artigo Pulsóes e destinos da pulsáo (1915b/2007), o desenvolvimento psíquico aos estímulos endógenos. À vista disso, podemos concluir que são as pulsóes, e não a excitação externa, os verdadeiros motores que levaram 
o psiquismo ao seu atual nível de desenvolvimento. Em consequência, a memória pode ser entendida como uma exigência da pulsão.

Feitas essas reflexôes, cabem aqui algumas explanaçôes. É sabido que Freud, no Projeto, tenta estabelecer uma psicologia nos moldes de uma ciência natural, e, portanto, os neurônios e a quantidade devem atender às explicaçóes mecânica e biológica. De acordo com Casanave (2008), ambos os pressupostos se complementam, contudo, a partir de uma certa hierarquia. Freud sustenta que as açôes humanas promovem, em geral, a redução da excitação, o que, por si só, resulta prazeroso e adaptativo. Assim, o fundamento biológico, ainda que independente, pode ser reduzido a princípios mecânicos. Freud serve-se, dessa forma, dos esclarecimentos biológicos para reforçar as teses mecânicas. A explicação dos processos psíquicos inconscientes, além de possuir uma justificativa mecânica e biológica, apresenta-se, também, por uma possível constatação evolucionista. Conforme Freud (1895/2007), acompanhando as formulaçôes darwinistas, podemos afirmar que os neurônios da memória são indispensáveis e, devido a isso, subsistem. Esta é apenas mais uma das formas, expostas pelo autor, de atribuir ao psiquismo os processos inconscientes, uma vez que a consciência náo pode ser comprovada a partir de tais explicaçóes.

No texto Formulaçóes sobre os dois princípios do acontecer psíquico, Freud trabalha o psiquismo com base em sua relação com o princípio do prazer e o princípio de realidade, e não mais pela teoria da inércia. Podemos vislumbrar uma modificação essencial no texto de 1911, quanto às formulaçôes do Projeto. Como já foi destacado, em 1895, Freud demarca a diferença entre princípio de inércia e princípio de constância, atribuindo a este último a característica de lidar com quantidades de excitação, enquanto o primeiro se relaciona ao rebaixamento total desta. Freud parece seguir o mesmo raciocínio do Projeto também na Interpretação dos sonhos. Em suas palavras, "[...] o aparato psíquico obedeceu primeiramente à ânsia de se manter sempre que possível exento de estímulos e por isso em sua primeira construçáo adotou o esquema do aparelho reflexo [...]" (FREUD, 1900/2007, p. 557).

É fundamental percebermos aqui que, em 1895 e em 1900, a função primária refere-se à esquiva do estímulo gerador de desprazer, e não à efetivação de um registro. No entanto, no texto de 1911, acerca dos funcionamentos psíquicos, Freud relaciona esse primeiro momento já a uma organização psíquica, ao princípio do prazer, e não ao princípio de inércia. Qual a principal distinção a propósito desses dois momentos da teorização freudiana, a saber, 1895-1900 e 1911? Parece-nos que, nos primeiros textos, Freud discorre sobre 
a constituição do psiquismo, da efetivação dos traços mnêmicos. Já em 1911, ele trabalha, desde o início, a respeito de um aparelho de memória. Dessa forma, o princípio organizador da vida psíquica, o princípio do prazer, que aparece pela primeira vez no texto de 1911, refere-se ao funcionamento do psiquismo enquanto portador dos traços mnêmicos.

Evocamos, reiteradamente, a relação existente entre memória e princípio de constância, a fim de evidenciarmos que ao funcionamento dos traços mnêmicos está atrelado um acúmulo de energia. Esse acréscimo de excitação com que os neurônios $\psi$ precisam lidar exige que os mesmos estejam repletos de determinada $Q$, de modo que obtemos "[...] a representação de um neurônio investido (Besetzt) [...]” (1895/2007, p. 342). Conforme Freud, a função secundária que corresponde aos neurônios da memória é possibilitada pela existência das barreiras de contato que se contrapóem ao escoamento de Q. Chegamos ao momento decisivo das elaboraçōes freudianas sobre a memória, no Projeto. Assim, se as barreiras de contato possibilitam à memória o seu funcionamento, isso não ocorre apenas pelo impedimento do livre fluxo de quantidade. Freud (1895/2007, p. 344), nesse momento, discorre acerca da existência de um "aprender-sobre (Ein über Erlernen)", com base na interconexão existente entre os traços mnêmicos. Desse modo, a memória está constituída pelas facilitaçôes (Bahnung) existentes entre os neurônios $\psi$, ou seja, as barreiras de contato, que, ao invés de dificultar, proporcionam aos neurônios da memória uma relação entre si. As facilitações entre os neurônios $\psi$ podem ser explicadas da seguinte maneira: os caminhos que são percorridos com maior intensidade ocasionam uma menor resistência dos neurônios. De tal sorte, na próxima vez que passar uma nova quantidade, eles serão novamente investidos (Besetzt).

Garcia-Roza (2001), ao discorrer sobre a importância do conceito de Bahnung, adverte quanto à diversidade de suas traduçóes, que, segundo o autor, ofusca o sentido do termo freudiano. Assim, para uma adequada leitura de Freud, é preciso entender esse Bahn não necessariamente no sentido de uma estrada, que preexiste ao caminhante, mas do ponto de vista de uma trilha, aberta pelos passos que a percorrem. O que está em jogo é essencialmente a ideia de uma recordação que se apresenta num momento posterior ao da inscrição, o que faz com que a evocação da lembrança se efetue, não pela presença constante do traço, mas por uma associação de envios e reenvios que trilham caminhos e possibilitam a memória. Em outras palavras, os traços mnêmicos precisam ser entendidos, essencialmente, como a condição de 
possibilidade da rememoração consciente. Não é por acaso, dessa forma, que Derrida (1967, p. 184) afirma: "Seja o que for que pensemos da fidelidade ou das rupturas futuras, esta hipótese (Bahnung) é notável [...]”. O filósofo chama atenção para o termo Bahnung, por ele destituir a ideia de uma memória fixa e presente à consciência ${ }^{5}$.

Nesse sentido, se Freud chega a equiparar o investimento (Besetzung) à facilitação (Bahnung), esse fato não implica, de forma alguma, uma apresentação dos traços mnêmicos como um sistema igualmente investido. $\mathrm{O}$ que ele assegura é a existência de uma facilitaçáo entre os neurônios $\psi$ que não pode ocorrer de forma idêntica. Conforme explica, se as barreirascontato $\psi$ estivessem constantemente facilitadas entre si, as características da memória não apareceriam. Desse modo, a memória se constitui, justamente, pela diferença existente nas facilitaçôes entre os neurônios encarregados da memória. Portanto, a memória freudiana explica-se, mais eficazmente a partir dos seus possíveis trilhamentos do que em decorrência de um traço a todo o momento investido.

\section{A CONSCIÊNCIA E A MEMÓRIA: DIFERENÇA ENTRE PERCEPÇÁO E REPRESENTAÇÁO}

A apresentação dos traços mnêmicos, no Projeto, é uma tentativa de exprimir o funcionamento do psiquismo à revelia de uma organização consciente, ou, pelo menos, representar os processos psíquicos $\psi$ com base em uma proeminência quanto à consciência. De acordo com Freud (1895/2007), a consciência não nos oferece um conhecimento completo nem confiável dos processos neuronais, e estes devem ser considerados, essencialmente, como inconscientes.

Não obstante, a importância dos neurônios da consciência não deixa de se impor ao pensamento freudiano e, mesmo tardiamente, é levada em consideração no Projeto. É, pois, no manuscrito de 1895 que, segundo Simanke e Caropreso (2005), Freud empreende a mais extensa reflexão sobre a consciência de toda sua

\footnotetext{
${ }^{5}$ A noção de memória em Freud inspira a ideia de écriture, proposta por Derrida. Além do Projeto, o filósofo utiliza-se, sobretudo, da Carta 52 , da Interpretação do Sonhos e do Bloco Mágico, para sustentar sua hipótese do psiquismo como uma escrita. Tal ideia precisa ser entendida a partir do movimento da différance, cujo neografismo com relação à palavra francesa différence obriga a que se recorra sempre à sua forma escrita, a fim de perceber o deslocamento ocorrido. O filósofo pretende, assim, conduzirnos, através desse novo termo, para uma nova noção de diferença que excede os limites de uma organização da consciência. Dessa forma, a memória, compreendida no bojo da différance, transcende a organização de um arranjo consciente.
} 
obra. Se, no início, assegura que qualquer saber psicológico necessita formular uma teoria sobre a memória, a problemática sobre os processos conscientes passa a ser uma segunda injunção: "Até aqui nada se disse sobre o fato de que toda teoria psicológica [...] precisa satisfazer mais um requisito fundamental. Ela tem de nos explicar tudo o que já conhecemos, da maneira mais enigmática, através de nossa consciência [...]" ( FREUD, 1895/2007, p. 352).

Assim, a um sistema que a princípio funcionava somente a partir dos neurônios da percepção e dos neurônios da memória soma-se um pensamento sobre a consciência; o aparelho é, desde então, diferenciado da seguinte forma: $\varphi, \psi$ e $\omega$. A ordem dos sistemas, ao mostrar-se, no Projeto nessa direção - $\varphi \psi \omega$ -, implica uma antecedência da representação com relação à consciência, sendo esta concebida somente como algo paralelo a apenas uma parte dos processos psíquicos. De acordo com Freud (1895/2007), a consciência é, sobretudo, o lado subjetivo de uma parte dos processos psíquicos, cuja ausência não deixa os eventos psíquicos inalterados. O que nos possibilita afirmar, à vista disso, uma anterioridade da memória no que tange à percepção. Desse modo, ambos os processos, os de origem interna e os de procedência externa, só se tornam conscientes após atravessar os registros da memória.

A problemática acerca da consciência gira em torno do que Freud denomina qualidades, que, por sua vez, possibilitam as sensaçóes conscientes. $\mathrm{O}$ autor recorre a três opçôes para o entendimento da origem das qualidades. A primeira opçáo diz respeito ao mundo externo, que logo é deixada de lado em decorrência da explicação de que a exterioridade comporta apenas massas em movimento. A segunda refere-se aos neurônios da percepção $\varphi$, mas essa escolha é, também, posta de lado, uma vez que os processos da consciência se situam em níveis mais elevados que os da percepção. A terceira dirige-se aos neurônios da memória $\psi$, no entanto, de acordo com Freud, nesse sistema só existem reprodução e recordação, e não qualidades. É em decorrência do abandono das três hipóteses sobre a origem das qualidades que Freud lança mão de um terceiro sistema, constituído pelos neurônios ômega. Salienta o autor: "Assim, reunimos ânimo suficiente para supor que haja um terceiro sistema de neurônios, neurônios $\omega$, que é excitado juntamente com a percepção, mas não com a reprodução, e cujos estados de excitação produzem as diversas qualidades" (FREUD, 1895/2007, p. 353).

A percepção consiste, essencialmente, na ocupação dos neurônios $\varphi$ por quantidades de excitação provenientes do exterior, cujo signo de qualidade, resultante dos neurônios $\omega$, possibilita o caráter consciente. Já as representaçóes 
são, conforme Freud (1915/2007), basicamente, traços mnêmicos investidos. Uma percepção está sempre relacionada tanto com a quantidade quanto com a qualidade; por outro lado, uma representação pode vir, ou não, acompanhada de qualidade, e, dessa maneira, ser consciente, ou seja, uma representação pode permanecer inconsciente.

Se a representação caracteriza-se, necessariamente, pela ocupação dos traços mnêmicos por um fluxo de quantidade, é digna de consideração a ideia de um traço mnêmico não investido. Conforme Laplanche e Pontalis (1992), a distinção entre traço e representação não se evidencia na obra de Freud, uma vez que a representação é caracterizada como um traço mnêmico investido, teríamos que pensar, em contrapartida, na existência de um traço que não receba investimento de nenhum dos sistemas psíquicos, nem mesmo do inconsciente. Poderíamos pensar, dessa forma, a representação como uma (re)ocupação dos traços mnêmicos.

Das distinções existentes entre percepção, representação e traço mnêmico, a de maior relevo diz respeito à diferenciação entre percepção e representação. Nessa perspectiva, de um lado temos a percepção e, do outro, representação e traço mnêmico. Segundo Casanave (2008), após a percepção, estabelecem-se os traços mnêmicos que poderão tornar-se rememoração consciente. Contudo, os traços mnêmicos náo resguardam, em si, as qualidades sensíveis dos objetos que se dão à percepção. $\mathrm{O}$ que objetivamos demarcar é que Freud diferencia a inscrição da percepção da imagem sensível do objeto, não havendo semelhança necessária entre traço e objeto. Em outras palavras, Freud distingue aquilo que apreendemos com base em nossas percepçóes do traço mnêmico, o qual identifica com a vida anímica.

\section{O CONCEITO DE $N$ ACHTRÄGLICH E O TEMPO DA MEMÓRIA FREUDIANA}

Freud discorre, pela primeira vez, a propósito do conceito de a posteriori na segunda parte do seu Projeto. Sua investigação inicia-se a partir de questóes trazidas pela histeria, mas que de forma alguma se restringem a ela. Segundo Freud, o funcionamento histérico está submetido a uma compulsão exercida por representaçóes hiperintensas (Überstark). Como quando emergem, na consciência, representaçóes (Vorstellung) as quais o contexto não justifica, ou mesmo quando o aparecimento de uma determinada representaçáo está associado a um desprendimento de afeto incompreensível. Da existência de uma representação hiperintensa decorrem dois fatos: 1) não é possível sufocar o 
aparecimento dessas representaçôes na consciência; 2) não se pode compreender a relação que a representação mantém com o desprendimento de afeto.

Suponhamos o seguinte: determinado indivíduo chora a partir do aparecimento de uma representação $A$, contudo, o indivíduo não consegue associar o motivo do seu choro ao surgimento de tal representaçáo; dessa forma, o ato de chorar é incompreensível para ele. Freud enfatiza que a solução para esse impasse reside no trabalho analítico, que consiste, sobretudo, em associar o choro a uma outra representação que o torne compreensível. Conforme ele, pelo trabalho analítico nos damos conta de que a representação $A$ demarca uma situação secundária ocorrida na mesma ocasião em que uma representação $B$ de fato ocasionou o choro. A relação entre a representação $B$ e o choro é inteligível para o indivíduo e este pode combater, mediante um trabalho psíquico complicado, os efeitos dessa representaçáo.

No entanto, como podemos entender a existência dessas representaçôes hiperintensas na consciência? A possibilidade de estabelecer uma diferença entre percepção e representação marca o deslocamento do processo primário para o processo secundário e, consequentemente, o advento do eu. Tanto na experiência de satisfação quanto na de dor é imprescindível uma diferenciação entre esses elementos. Isto devido à equivalência entre investimento e facilitação; quer dizer, o investimento numa determinada representação pode ocasionar o fenômeno da alucinação, que consiste em tomar uma representação pelo próprio objeto. Desse modo, todos os processos de pensamentos que ocorrem no eu têm por finalidade estabelecer uma relação de identidade entre uma percepção - ou um complexo perceptivo - e uma representação - ou um complexo mnêmico. Existem, conforme Freud (1895/2007), dois tipos de pensamento: o pensamento reprodutor e o cognitivo. A diferença entre ambos reside na possibilidade, ao final do processo de identificaçáo, de se realizar um investimento na representação. Caso esse investimento ocorra, trata-se de um pensamento reprodutor; caso contrário, de um pensamento cognitivo.

No processo do pensamento, há três relaçôes possíveis entre a representação e a percepção: a de identidade, a de semelhança e a de diferença. No caso de identidade, existe uma coincidência entre o investimento da representação e a percepção desse objeto. Não é necessário, portanto, nenhum trabalho cognitivo, devido à sobreposição dos dois tipos de investimento. Trata-se, conforme Freud, de uma situação sem valor biológico. No caso da diferença, não existe nenhuma relação de identidade entre uma representação e uma percepção. Aqui nos detemos acerca da hipótese da semelhança. 
O caso da semelhança tem mais valor do ponto de vista biológico por dar origem ao processo do pensamento. O investimento de uma representação, nessa ocasião, está associado à percepção de um objeto externo que não condiz de todo, somente em parte, com a representação. Contudo, adverte Freud, a representação do objeto não é pontual, trata-se, ao contrário, de um complexo representacional, onde há a parte fixa chamada (Das Ding) e uma variável, que é denominada atributo. A parte fixa está relacionada às representaçóes internas do indivíduo, enquanto seu predicado está conectado à percepção externa. Nesse sentido, uma representação não é apenas a cópia de um objeto externo, mas um complexo no qual existiria uma parte concernente ao próprio indivíduo (GABBI, 1987).

Conforme Freud (1895/2007), o caso de semelhança é mais comum que o de identidade e propicia ao indivíduo um aprendizado valioso: não se deve, dessa forma, iniciar um processo de descarga motora antes que a representação de objeto desejado e a percepção deste na realidade coincidam. Freud esclarece esse processo da seguinte forma: seja $a-b$ uma representaçáo desejada e $a-c$ a percepção do objeto. $\mathrm{O}$ elemento comum, ou seja, $a$ é a representação-coisa, que permanece sempre inconsciente. Freud denomina “coisas” os restos subtraídos à apreciação (1895/2007, p. 279). Quanto a isso, Gabbi (1987) sustenta que as coisas escapam do julgamento porque as mesmas o tornam praticável. Desse modo, o dispositivo denominado julgamento, que faz a conexão entre os predicados $b$ e $c$, é propiciado por Das Ding, a parte fixa do complexo representacional formado a partir das primeiras inscriçóes de satisfação e de dor.

Em decorrência, a existência de representaçôes hiperintensas (Überstark) na consciência diz respeito não somente ao complexo perceptivo, mas refere-se, todavia, ao complexo desiderativo que comporta a memória. Segundo Casanave (2008), nós percebemos não somente condicionados pelos estímulos externos, mas também pela nossa memória.

Assim, se no funcionamento normal também é possível constatar a existência dessas representaçóes, que Freud denomina compulsão neurótica simples, é preciso colocá-las em contraste com as representações histéricas a fim de explicitar a especificidade destas últimas. Na compulsão normal, é possível compreender a associação de ideias e a devida liberação de afeto. $\mathrm{O}$ que existe de comum entre os dois tipos de compulsão é a impossibilidade de o indivíduo se desfazer dessas representaçóes mediante o trabalho de pensar, o que caracteriza seu caráter de insolubilidade. 
É interessante demarcar aqui uma outra diferença traçada por Freud entre a compulsão normal e a histérica. Se a compulsão normal é compreensível tanto do ponto de vista do afeto a ela associado quanto com relação à conexão entre as representaçôes, o estudioso afirma, ainda, que a representação simples costuma sucumbir ao fator temporal, ao contrário da compulsão histérica, deixando, dessa forma, de exercer impacto após o transcorrer do tempo. Vemos, desse modo, que o conhecido provérbio popular de que a cura está ligada ao tempo não condiz de todo com o funcionamento histérico. Em consequência, a perduração de uma compulsão é que é patológica, e não a compulsão em si.

Freud explica a existência de representaçôes hiperintensas no sintoma neurótico a partir de dois processos: o recalque e a formação de símbolo que a ele se segue. Uma determinada representação é substituída por outra, com a qual está associada, sem que a consciência tenha conhecimento desse fato. Dessa maneira, conforme o exemplo do choro, $B$ foi substituído por $A$, isto é, $A$ passa a ser o símbolo de $B$. Em decorrência dessa substituição, $A$ passa a produzir efeitos inadequados. Outra vez, estamos na presença de um processo que igualmente ocorre no funcionamento normal. Freud nos apresenta, pois, o exemplo da bandeira que é o símbolo de uma nação pela qual o soldado se sacrifica. Em contrapartida, a formação do símbolo na histeria se comporta de outro modo. O histérico nada sabe daquilo que se apresenta a ele enquanto um pensamento compulsivo, desconhecendo, assim, a associação $A-B$. Como resultado, $A$ adquire um caráter compulsivo enquanto $B$ permanece recalcada. Houve, nesse caso, uma total substituição da coisa pelo símbolo. Segundo Freud (1895/2007, p. 397), "[...] a cada compulsão corresponde um recalque; a toda irrupção excessiva na consciência, há uma amnésia correspondente”.

$\mathrm{O}$ que ocorreu no psiquismo que fez com que $B$ fosse substituída por $A$ ? Freud responde a essa questáo com base em duas prerrogativas: 1 ) $B$ sofreu recalque em decorrência do afeto desprazeroso que despertava; 2) as representaçóes recalcadas são provenientes da vida sexual. Nesse sentido, as representaçóes sexuais são recalcadas devido ao desprazer a elas associado. Todavia, Freud já havia formulado uma defesa primária, que consiste em fazer com que uma determinada representação, que ocasione desprazer, seja inibida. Nas palavras do autor, "[...] a corrente de pensamento dá a volta (Umkehren) assim que se choca com um neurônio cujo investimento desprende desprazer" (1895/2007, p. 398). Desse modo, podemos nos perguntar: por que as representaçóes sexuais náo foram inibidas, sofrendo, ao invés disso, 
recalque? Segundo Freud, é apenas no momento da irrupção da adolescência e, consequentemente, da sexualidade que essas representaçóes adquirem um caráter desprazeroso. Por consequência, a essas representaçôes não estava associado, a princípio, um grande desprendimento de afeto.

Existe, portanto, no desenvolvimento psíquico, um atraso da sexualidade com relação às outras funçôes do sujeito, ela surge apenas com o advento da adolescência. Desse modo, temos duas situaçôes: a vivência de uma experiência e a recordação que concede a essa experiência um outro caráter. Voltemos à questão: por que determinada representação sofre recalque e não é, ao contrário, inibida? A resposta encontra-se associada diretamente ao retardamento da função sexual. Uma representação só pode ser inibida se estiver referida a uma situaçáo vivida e compreendida pelo indivíduo. Como a sexualidade confere um sentido retroativo à representaçáo, no momento em que a vivência de fato ocorreu, seu sentido não podia ser apreendido enquanto tal, visto que este ainda nem tinha sido atribuído. Freud concede a essas experiências uma condição irrefutável, elas necessitam ser, por conseguinte, vividas. Assim, o passado náo pode ser completamente indeterminado, o efeito de causalidade retroativa diz respeito mais precisamente à arrumação dos fatos em si.

O que podemos compreender, por esses enunciados? A defesa normal do indivíduo, propiciada pelo advento do $\mathrm{Eu}$, diz respeito mais às percepçóes do que à memória. Podemos vislumbrar, uma outra vez, a fragilidade do indivíduo frente ao processamento interno da realidade exterior. Ora, Freud estabelece que a inibição está relacionada à atenção que o Eu dirige às percepçóes que possibilitam o desprendimento de um afeto desprazeroso. Contudo, no caso da histeria, o que se apresenta não se reporta à percepção, mas sim à memória. Desse modo, Freud afirma que não é nenhuma percepção, mas um traço mnêmico, o que inesperadamente desprende desprazer $(1895 / 2007)$. Cabe à histeria, portanto, um tipo de defesa que excede a defesa normal e que favorece outras consequências. Assim o veremos no caso Emma.

A formação do símbolo histérico e, dessa forma, da representação hiperintensa, é exemplificada por Freud a partir do caso Emma. Conforme explica, a paciente encontra-se impossibilitada de frequentar sozinha uma loja. Uma recordação apresenta-se como fundamento para a formação desse sintoma. Quando tinha doze anos, Emma relata ter ido a uma loja comprar alguma coisa e, nessa ocasiáo, vê dois balconistas que riem entre si, o que faz com que ela deixe o local com um sentimento de terror. Dessa recordaçáo, transcorrem alguns pensamentos: os dois empregados estavam rindo de seu 
vestido e um deles despertou nela uma atração sexual. Em contrapartida, essas lembranças não podem justificar nem a compulsão nem a formação do sintoma. Existiria, pois, uma outra recordação a ela associada. Emma relata, então, que quando tinha apenas oito anos foi a uma mercearia comprar doces e que foi molestada pelo vendedor. A paciente narra, além disso, que teria ido uma outra vez à mesma mercearia e que se recriminaria por esse fato, como se quisesse provocar um outro atentado.

Ambas as cenas se entremeiam na formação do sintoma. É válido ressaltar que Freud náo outorga um valor de realidade absoluta a nenhuma dessas recordaçôes. A cena dos balconistas rearranja a da mercearia, conferindolhe um outro sentido. Desse modo, é apenas a posteriori que a cena mais antiga adquire um caráter traumático. Nas palavras de Freud: "A lembrança desperta (coisa que naquele tempo era incapaz de fazer) um desprendimento sexual que se transpõe em angústia” (1895/2007, p. 401). Nesse sentido, o que é demarcado por Freud é a proeminência da recordação em detrimento da vivência. Dito de outra forma, a memória dá origem a um afeto que a própria vivência não foi capaz de produzir. A cena da mercearia, quando Emma tinha oito anos, não é traumática em si: é somente a partir de um segundo momento, após a adolescência, que essa recordação adquire um caráter desprazeroso.

Como Freud explica a associação existente entre as duas cenas? O elemento associativo, demarcado por ele, é o riso, pois quando Emma entra na loja e presencia os dois balconistas que riem entre si, reporta-se, inconscientemente, à primeira cena da mercearia, em que o empregado também ri. Essa cena já pode ser compreendida e vivenciada pela paciente como sexual. Assim, é a compreensão do seu caráter a posteriori que concede à cena da mercearia um maior investimento pulsional. Desde esse ponto, o complexo representacional que diz respeito à cena de seduçáo sofre recalque e a excitação sexual é transformada em angústia. $\mathrm{O}$ desprendimento sexual, ressalta Freud, que se apresenta na consciência é atestado pelo fato de Emma sentir-se atraída pelo balconista. O estado de angústia aderiu-se ao medo de que os balconistas repetissem o atentado inicial. Em contrapartida, o processo de recalque promoveu o deslocamento do investimento na representação do atentado para a representação do vestido. $\mathrm{O}$ vestido torna-se o símbolo da cena de sedução, e esse símbolo passa a ser, como já foi destacado, inconsciente para a paciente.

Logo, quais as consequências do recalque? A partir da análise do caso, o resultado principal desse processo se evidencia: o sujeito é desapossado de sua memória e, desde então, não mais tem acesso às representaçôes que tornariam 
compreensíveis seus atos. Vejamos: Emma não percebe o sentido evocado pelo riso entre os empregados, não mais consegue trazer à consciência a recordação do atentado, perdendo, assim, a relação consigo e com o outro, pois seus atos estão dissociados de sua fala.

Com relação à formação da representação hiperintensa, Freud assegura, não obstante, que "[...] a facilitação, ou melhor, a antiguidade, chegou a prevalecer. Com este esquecimento, em todo semelhante ao que ocorre no sonho, desaparece a seleção, a adequação ao seu fim, e a lógica do curso" (1895/2007, p. 405). Freud afirma, à vista disso, que há uma analogia entre neurose e sonho. Contudo, no sonho existe apenas desejo, mas não recalque, sendo o sonho um processo que ocorre todas as noites e com todos os homens. Mais precisamente, o sonho seria a via régia do desejo. Já, na histeria, o recalque constitui o processo chave para a compreensão do sintoma neurótico. A histeria estaria delineada, além disso, a partir do trauma e da precocidade sexual. Sonho e neurose, dois processos que possuem, entre si, muitas analogias, mas também algumas distinçôes.

No marco da teoria da sedução, o trauma se daria da seguinte forma: uma primeira cena de sedução não produziria efeitos psíquicos, devido à imaturidade do indivíduo, enquanto uma segunda cena, muitas vezes inocente, mas capaz de associar-se à primeira e ocorrida num período em que o indivíduo já é capaz de compreender e vivenciar o caráter sexual, reatualiza a cena primária, conferindolhe um afeto desprazeroso que aciona a defesa do indivíduo. Conforme Simanke, o trauma emergiria de um exterior interiorizado, atualizado pelo trabalho mnêmico: “'Os histéricos sofrem de reminiscências', e de fato pode-se descrever o movimento inicial da obra de Freud como a edificação de uma teoria da memória que dê conta dessa afirmação" (SIMANKE, 2009, p. 230).

No período de transição (após o abandono da teoria da sedução e a formulação do conceito de fantasia como realidade psíquica), dois conceitos fundamentais somam-se à realidade psíquica para dar a esta uma autonomia em face da cena traumática. Um desses conceitos é formulado pouco tempo depois do abandono da teoria da sedução: trata-se do complexo de Édipo. Freud (1897/2007, p. 316) chega a essa formulação através de sua autoanálise. Nela verifica que, também no seu caso, “[...] a paixão pela mãe e o ciúme do pai [...]" são constitutivos. Passa, pois, a considerar o evento como universal na infância, o que destitui o fator acidental da hipótese de sedução. Nesse período, começa a ficar insustentável a teoria de que a sexualidade incidiria 
apenas na puberdade. Assim, a teoria da sexualidade infantil começa a se insinuar no pensamento freudiano.

O crescente lugar de destaque que a fantasia passa a ter, na explicação do psiquismo, com relação à teoria da sedução, acentua mais ainda o caráter inventivo (Erdichten), e náo simplesmente reprodutivo, da memória. Dito de forma mais precisa, o traço mnêmico é reinscrito com base na fantasia, criando, desde então, uma memória. Na teoria freudiana, o passado, que a memória conserva, ganha vida a partir da fantasia (FREUD, 1907 [1906]/2007, p. 15).

PEIXOTO, Maria Celina Lima; OLIVEIRA Débora Passos. The project of Freudian memory: a review of the constitution of this notion in the early days of psychoanalysis. Trans/Form/Ação, Marília, v. 35, n. 2, p. 257-276, Maio/Ago., 2012.

\begin{abstract}
The present work deals with the constitution of the notion of memory in Freudian theory, primarily making use of the elaboration developed in the Project for a scientific psychology. We aim to point out that Freud subverts the problem of the concept of memory, giving this idea a creative character that differs from the mere representation of an object contained in material reality. In Freud, memory goes beyond what is commonly understood as evocation, i.e., memory is not restricted to a recovery of perception. If memory is considered to be the psyche itself, it is its relationship with drive and later with the notion of Nachträglich that enables the realization of memory appropriate to psychoanalysis itself. Thus, we make it explicit that memory in Freud is both an imperative of drive and of the unfolding of the effects of a psychic temporality. Even though Freud departs from a strictly theoretical construction associated with the natural sciences, a closer examination of his formulations from this period helps us understand how he constructs a theory that, at least at first, had the ultimate goal of clarifying issues regarding the notion of memory.
\end{abstract}

KEYWORDS: Memory. Perception. Drive. Nachträglich.

\title{
REFERÊNCIAS
}

CASANAVE, Carlota. M. I. L. As tramas de Mnemosine: a memória nos primórdios da teoria freudiana. 2008. Tese (Doutoramento) - Instituto de Filosofia e Ciências Humanas, Universidade Estadual de Campinas, Campinas, São Paulo, 2008.

DERRIDA, Jacques. Freud e a cena da escritura. In: A escritura e a diferença. São Paulo: Perspectiva, 1967.

FREUD, Sigmund. Fragmentos de la correspondencia con Fliess. In: . Edição das Obras Completas da Amorrortu Editores. Buenos Aires: Amorrortu, vol. I, (1892-1899), 2007. 
Sigmund. Proyeto de psicología. In: Edição das Obras Completas da Amorrortu Editores. Buenos Aires: Amorrortu, vol. I, (1895) 2007.

. Sigmund. La interpretación de los sueños. In: Edição das Obras Completas da Amorrortu Editores. Buenos Aires: Amorrortu, vol. V (1900) 2007.

- Sigmund. Formulaciones sobre los dos principios del acaecer psíquico. In: . Edição das Obras Completas da Amorrortu Editores. Buenos Aires: Amorrortu, vol. XII (1911) 2007.

Sigmund. Lo inconciente. In: Edição das Obras Completas da Amorrortu Editores. Buenos Aires: Amorrortu, vol. XIV (1915a) 2007.

Sigmund. Pulsiones y destinos de pulsión. In: Edição das Obras Completas da Amorrortu Editores. Buenos Aires: Amorrortu, vol. XIV (1915b) 2007.

. Sigmund. Más allá del principio de placer. In: Edição das Obras Completas da Amorrortu Editores. Buenos Aires: Amorrortu, vol. XVIII (1920) 2007.

. Sigmund. Esquema del psicoanálisis. In: Edição das Obras Completas da Amorrortu Editores. Buenos Aires: Amorrortu, vol. XXIII ([1940]/1938) 2007.

GARCIA-ROZA, L.A. Introdução à metapsicologia freudiana 1. Rio de Janeiro: Zahar, 2001. GABBI JÚNIOR, Osmyr. F. Projeto para uma psicologia científica: máquina falante ou fala maquinal? Discurso: Rev, Depto, Filo, USP, São Paulo.Vol.16, p. 95-129, 1987.

LAPLANCHE, J.; PONTALIS, J-B. Vocabulário e Psicanálise. São Paulo: Martins Fontes, 1992. ROSA, José.G. Grande sertão: veredas. Rio de Janeiro: Nova Fronteira, 2001.

SIMANKE, Richard. A formação da teoria freudiana das psicoses. São Paulo: Loyola, 2009. ; CAROPRESO, Fátima. O conceito de consciência no "Projeto de uma psicologia" de Freud e suas implicaçóes metapsicológicas. Trans/form/ação: Revista de Filosofia / Universidade Estadual Paulista, 28 (1): p. 85-108, 2005.

Recebido em: 20.01.2012

Aceito em: 25.02.2012 